\title{
Petrophysics from the air to improve understanding of rock properties in the UK
}

David Beamish

British Geological Survey, Keyworth, Nottingham, NG12 5GG, UK.

First Break, 2013, 31, 63-71. (December 2013)

David Beamish (dbe@bgs.ac.uk)

British Geological Survey, Keyworth, Nottingham NG12 5GG, UK

Tel: +44(0) 1159363432

Fax: +44(0) 1159363437

\begin{abstract}
Electromagnetic geophysical applications exploit a petrophysical relationship governing the electrical properties of rocks. Given the extensive nature of many airborne electromagnetic surveys it seems natural to classify, and hence simplify, the spatially aggregated conductivity information on the basis of rock lithology. This provides an important link between lithological rock parameters and the petrophysical parameters controlling bulk conductivity. This classification procedure has been applied to over $8 \mathrm{M}$ conductivity estimates obtained from airborne surveys conducted in the UK over a period of 10 years. The analysis has provided new information on the conductivity characteristics of many UK geological formations and allowed a new UK national map of bedrock conductivity to be developed. Here we highlight the complex conductivity variations observed in mudstone and shale rocks across a Carboniferous basin. The potential interplay of increasing conductivity due to clay content and decreasing conductivity due to the presence of pore-scale hydrocarbons is noted. The geological-geophysical analysis described is a new procedure that provides a framework for further detailed petrophysical understanding of rock properties at depths accessible to EM techniques.
\end{abstract}




\section{Introduction}

A major application of petrophysics lies in the study of reservoirs for the hydrocarbon industry. Petrophysical investigations are used to understand the rock properties of the reservoir, particularly how pores in the subsurface are interconnected and how they control the accumulation and migration of fluids and hydrocarbons. Petrophysical studies typically evaluate rock properties by acquiring a suite of well log well measurements. These studies are then combined with geological and geophysical studies to give a fuller understanding of the reservoir.

The purpose of the present study is to review and understand the petrophysical information contained in a variety of electromagnetic (EM) geophysical methods that provide estimates of subsurface electrical conductivity/resistivity. The rock property estimated in the EM case is a bulk, or volumetric, average conductivity $\left(\sigma_{t}\right)$ that also has a specific role in petrophysical well-log analysis. Thus, for example, quite simple methods exist for the estimation of total organic content based on resistivity logs (Passey et al., 1990).

After a brief review of the theoretical basis for interpretation of electrical conductivity, the manner in which different EM methodologies exploit the underlying petrophysical dependencies are described. Rock classifications based on lithological descriptions inherently address the grain size and clay/silt content of rock and it is noted that these petrophysical parameters also underpin theoretical descriptions of the electrical properties of the rock. A lithological approach to the classification of bedrock conductivity data obtained from AEM survey data in the UK is therefore undertaken. At the large scale, the analysis has provided a new national 1:625k map of bedrock conductivities. At the more detailed scale, the application of such procedures has provided new information on the lithological behaviour of the conductivity of many UK geological formations.

The major rock types in the UK (by area) are associated with mudstone and mixed lithology formations such as Sand-Silt-Clay. An example of the detailed conductivity assessment of mudstone and carbonaceous shale formations is presented. The shale formations form current hydrocarbon prospects for tight hydrocarbons (shale-gas) at deeper levels in the associated Carboniferous basin.

\section{Theoretical basis}

The use of formation (or bulk) conductivity to investigate the subsurface relies on an ability to understand the petrophysical factors that control it in a given geological setting. Archie (1942) indicated that the bulk material conductivity is related to pore fluid conductivity $\left(\sigma_{f}\right)$, fractional, effective porosity $(\phi)$ as the first term of the empirical and generic expression:

$\sigma_{t}=\sigma_{f} \phi^{m}+\sigma_{A}$

where a fully-saturated formation is assumed. The Archie equation is taken from deLima and Sharma (1990). The porosity exponent $(\mathrm{m})$, or cementation factor, depends on the geometric factor of grain shape and packing. In practice, even the cleanest formations often contain small amounts of clay, or argillaceous bands, which can exert a significant influence on $\sigma_{t}$. The presence of clay minerals in 
many rocks puts additional charge carriers in the fluid adjacent to solid surfaces, causing additional conduction along the surface, which is confined to a thin layer known as the electric double layer.

The Archie equation may then be extended to include an additional, and additive, term $\left(\sigma_{A}\right)$ to account for any grain surface conduction effects operating at the pore scale. Waxman and Smits (1968) generalized the electrical behaviour of shaly-sands into a further empirical equation by assuming the surface conduction to be parallel with the bulk conduction for all values of bulk conductivity. The additional term may then be expressed as a product of clay volume and clay conductivity (see Waxman and Smits (1968) and deLima and Sharma (1990) for details).

Archie's expression laid the foundation for many of the modern well log interpretation schemes used by the hydrocarbon industry. There exist many studies and discussions of the manipulation of equation (1) and variants using well-log data, usually at depths associated with hydrocarbon source rocks. These petrophysical studies also benefit from additional information including rock lithology, density and seismic attributes. This type of petrophysical control cannot be exercised in the majority of EM geophysical studies considered here and equation (1) is limited to qualitative use only.

\section{EM geophysics}

Electromagnetic geophysical measurements provide measurements and, subsequently, models of subsurface $\sigma_{t}$. A significant recent EM development has been in the introduction and use of marine Controlled Source EM (CSEM) systems. Such systems are now used as form of direct-detection of hydrocarbons essentially by exploiting the fluid conductivity term of equation (1). In these studies, the detection of an increase in bulk resistivity caused by displacement of pore fluids by hydrocarbons provides the basis of the methodology (Eidesmo et al., 2002). It is acknowledged that because of petrophysical complexity, 'direct-detection' is ambiguous unless additional information (e.g. from equation 1 ) is provided. Thus even in a relatively simple material such as the North Sea Chalk, seismic survey constraints (e.g. seismically derived porosity) together with assumptions regarding degree of saturation, may be required to obtain a successful interpretation of the spatial behaviour of a deep subsurface model of $\sigma_{t}$ (MacGregor, 2012).

We now consider more conventional EM measurements designed to provide near-surface bedrock assessments of subsurface $\sigma_{t}$. In reality, because of the general lack of additional control, the EM assessment of bedrock is potentially more challenging than that of marine CSEM marine surveys. The same principles of petrophysical ambiguity exist but most routine EM surveys do not benefit from the same level of required interpretation control available in the deeper hydrocarbon studies. Here we consider airborne EM (AEM) measurements that provide assessments of $\sigma_{t}$ to depths of several hundred metres. The long standing application of such systems has been in relation to the direct-detection of concealed mineralised zones. In this context, Archie's relationship is modified by the inclusion of an additional multiplying term for the rock matrix conductivity (i.e. a perfectly insulating rock matrix cannot be assumed).

More recently time-domain and frequency domain AEM surveys have been undertaken for both joint resource and environmental applications. In the environmental context, the fluid conductivity $\left(\sigma_{f}\right)$ together with the additional surface conduction term $\left(\sigma_{A}\right)$ play a key role. In a similar context to the direct-detection of hydrocarbons, the displacement of clean pore fluids by more conductive 
fluids in aquifers allows subsurface flow paths from industrial source concentrations (e.g. landfills, chemical processing plants, coal spoil) to be mapped over many kilometres. Figure $1 \mathrm{~b}$ shows the subsurface conductivity distribution obtained using AEM survey data in the vicinity of a small active landfill on the Mauchline Sandstone in Ayrshire, Scotland. A conductivity isosurface set at a value > $18 \mathrm{mS} / \mathrm{m}$ reveals a conductive leachate zone (assumed) below the landfill zone and a compact southerly trending plume at depths below $20 \mathrm{~m}$, presumably following the hydrogeological gradient within the aquifer. Although a small facility, during the year of the survey (2004), the landfill emitted an estimated $1.17 \mathrm{MKg}$ of methane.
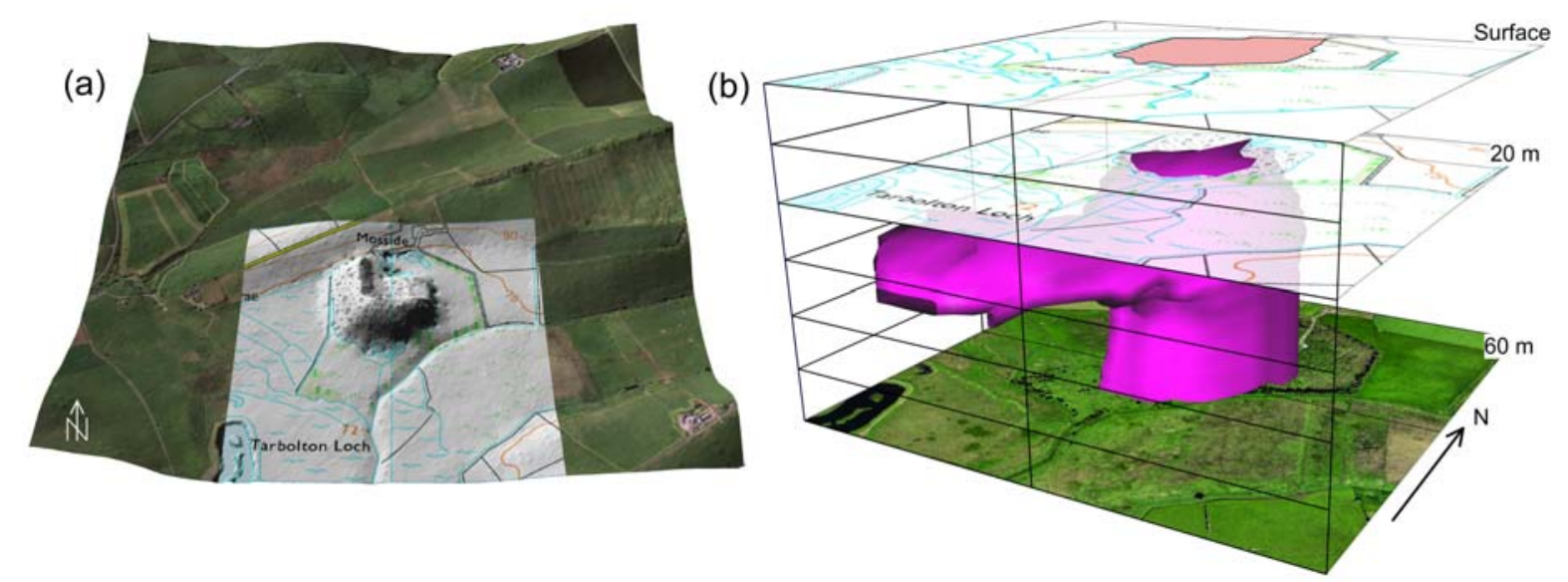

Figure 1 Example of a shallow pollution plume from a small landfill operating above a sandstone formation. (a) a $2 \times 2 \mathrm{~km}$ perspective view (on a DEM) of the Tarbolton landfill location with a $1 \times 1 \mathrm{~km}$ area highlighted using a 1:10k map. (b) perspective view of a conductivity isosurface (values $>18 \mathrm{mS} / \mathrm{m}$ ) within the $1 \times 1 \mathrm{~km}$ landill area. The at-surface polygon identifies the landfill.

Airborne surveys inherently provide information that extends from the local to the regional scale. Both the detection and interpretation of environmental effects are most effective when the degree of ambiguity is simplified e.g. when a single uniform lithology forms the host rock. Thus, within the Sherwood Sandstone aquifer in northern Nottinghamshire, plumes derived from every coal spoil zone can be traced over many kilometres (Beamish, 2002; Beamish and Klinck, 2006).

\section{Lithology}

Thus far, the porosity and cementation factor $(\mathrm{m})$ parameters of equation $(1)$ have not been discussed. As noted previously, $m$ depends on the geometric factor of grain shape and packing while primary porosity depends on grain size. Geological mapping nomenclature (e.g. Hallsworth and Knox, 1999) uses a range of rock characteristics to fully classify a specific formation. An important component in the procedure is the crystal/grain size together with the degree of sorting (rather than packing). Descriptions of the physical properties of sedimentary rocks involve qualifiers relating to a consideration of grain size and grain size parameters, grain morphology, fabric and porosity. A grain size scheme used for UK rock characterisation identifies sediments as boulder-gravel (> $256 \mathrm{~mm}$ ) through to clay $(<0.004 \mathrm{~mm})$ particles. 
Traditionally, geologists have divided sediments into four size fractions that include gravel, sand, silt, and clay, and classified these sediments based on ratios of the various proportions of the fractions. Definitions of the fractions have long been standardized to the grade scale described by Wentworth (1922). To classify sediment samples, Shepard (1954) divided a ternary diagram into ten classes. Shepard's diagram follows the conventions of all ternary diagrams. For example, Shepard's 'Clays' contain at least $75 \%$ clay-sized particles. 'Silty Sands' and 'Sandy Silts' contain no more than $20 \%$ clay-sized particles, and 'Sand-Silt-Clays' contain at least $20 \%$ of each of the three components.

A ternary diagram that might be used to classify Sandstones, Siltstones and Clay according to the proportions of grain sizes present is shown in Figure 2a. The end members would have defined grain sizes of sand from $2 \mathrm{~mm}$ (very-coarse) to $0.32 \mathrm{~mm}$ (very fine), silt from 0.032 to $0.004 \mathrm{~mm}$ and clay < $0.004 \mathrm{~mm}$. Rock mixtures with specific proportions might then be classified as shown. Theoretically geophysical measurements when geologically classified can provide statistical distributions of the bulk conductivity of each of the 10 lithologies shown. Figure $2 \mathrm{~b}$ shows a ternary image of median estimates of bedrock conductivity (discussed later) formed by the single lithology end members Sand, Silt and Clay. The conductivity values used are empirical and are taken from the study by Beamish (2013). The values used are Sand $(5.4 \mathrm{mS} / \mathrm{m})$, Silt $(11.4 \mathrm{mS} / \mathrm{m})$ and Clay $(132.1 \mathrm{mS} / \mathrm{m})$.
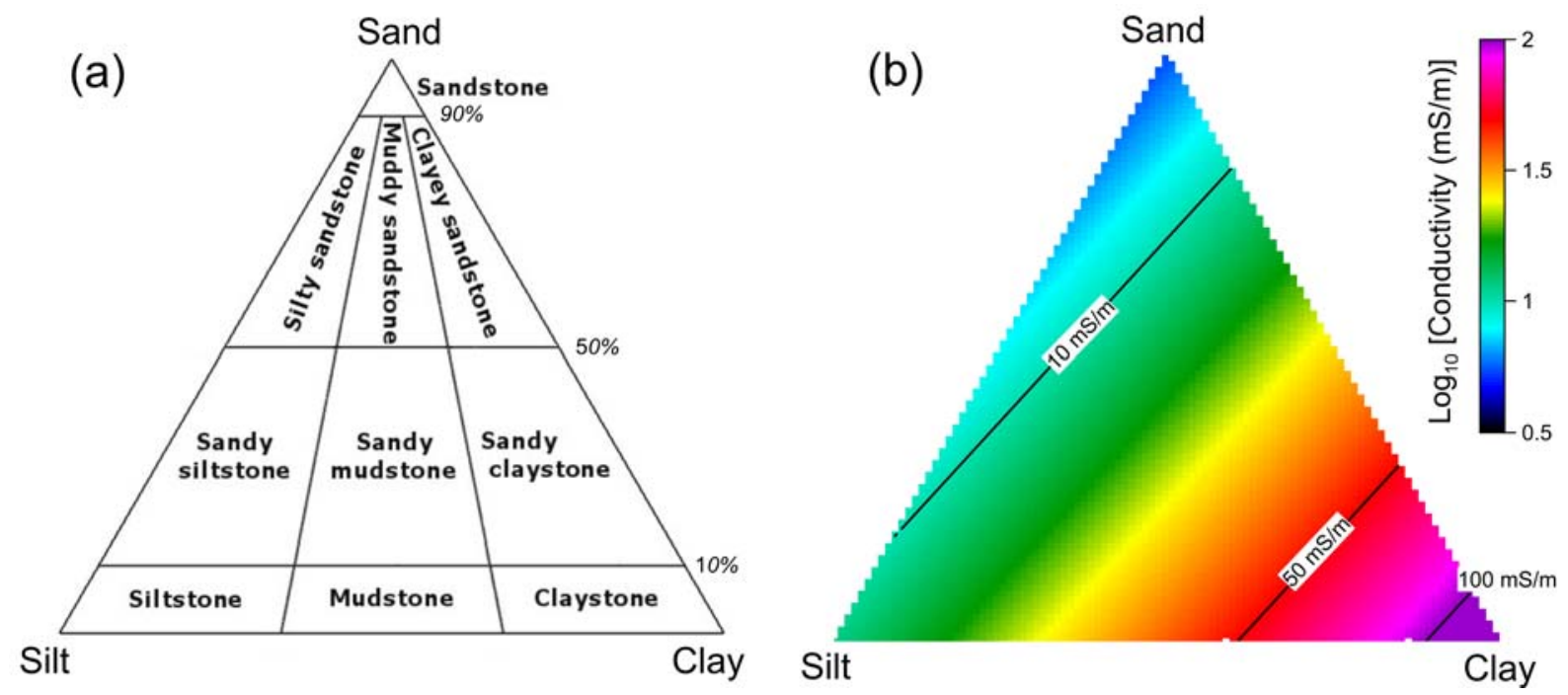

Figure 2 Ternary diagrams with end members of Sand, Silt and Clay. (a) a reference 10 class lithological distribution after Shepard (1954). (b) conductivity variations obtained by defining end member conductivities to Sand, Silt and Clay.

On the basis of equation (1) we would anticipate $\sigma_{\text {sand }}<\sigma_{\text {silt }}<\sigma_{\text {Clay }}$ when clay conduction dominates over any fluid conductivity effects and this is what we observe in the studies described below.

\section{AEM conductivity data}

Over the past decade, a number of high-resolution airborne geophysical surveys have been conducted across onshore UK (Peart et al., 2003; Beamish and Young, 2009). These High Resolution Airborne Resource and Environmental (HiRES) surveys have typically acquired radiometric (gammaray spectroscopy), magnetic and electromagnetic (conductivity) measurements at $200 \mathrm{~m}$ line spacings and at low altitude ( $60 \mathrm{~m})$. Due to their systematic coverage, the airborne conductivity 
data provide almost continuous information across each survey area with a typical along flight line sampling of less than $15 \mathrm{~m}$.

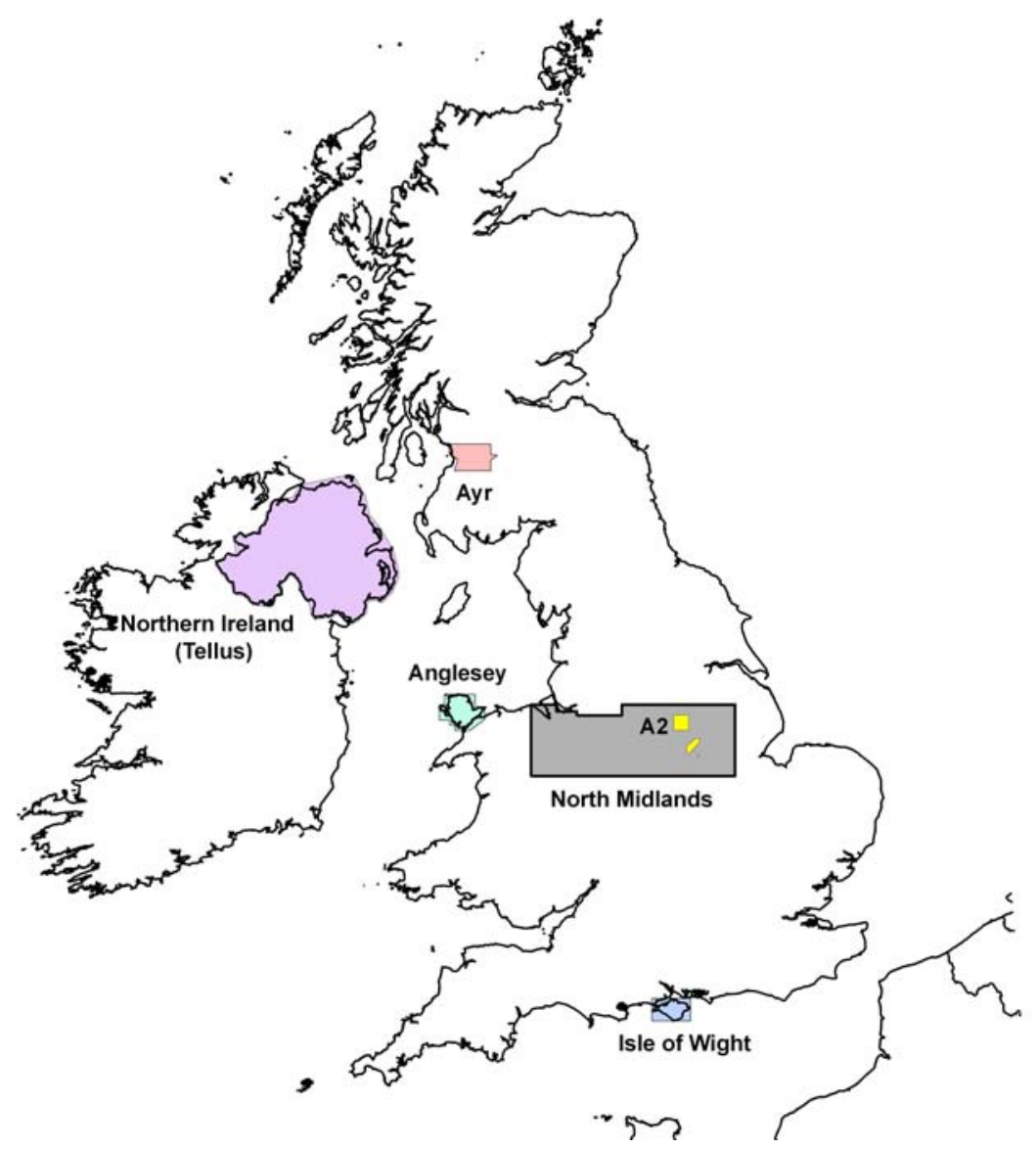

Figure 3 HiRes airborne geophysical survey areas in the UK (1998-2009). The North Midlands survey did not acquire active EM data.

The original North Midlands survey of 1998 was largely acquired at lower spatial resolution (400 m line spacing) and at a higher elevation $(90 \mathrm{~m})$ than later surveys. The survey did not include active frequency domain EM measurements and is not considered further here. AEM data converted to apparent conductivity from the remaining 5 surveys provide the framework for lithological assessments. The term apparent conductivity is used to denote that a vertically uniform, half-space conductivity is assumed.

Two common EM acquisition frequencies of $\sim 3 \mathrm{kHz}$ and 12-14 kHz were maintained from 1999 onwards. The lower frequency of $3 \mathrm{kHz}$ provides the larger depth of investigation. Beamish (2004) describes the volumetric footprints (skin-depths) of the AEM system considered here. Each measurement may typically be associated with a principal area of sensitivity of less than $100 \times 100 \mathrm{~m}$ over the ground surface. Each measurement typically assesses a subsurface volume in excess of $100,000 \mathrm{~m}^{3}$. Across the UK surveys, there is no fixed depth of investigation but the $3 \mathrm{kHz}$ data should be regarded as providing an assessment of 'near-surface' bedrock electrical conductivity except at locations where thick accumulations of conductive superficial deposits occur.

\section{Lithological attribution of AEM conductivity data}


Existing digital UK geological lexicons provide both lithostratigraphical (LEX-RCS) and lithological (RCS, Rock Characterisation Scheme) codes. The latter classification is simpler (less classifications) and provides an inherent association with grain-size and clay content as described previously. Beamish and White (2012) compared procedures and results obtained for both LEX-RCS and RCS attribution at a 1:50k scale using the Isle of Wight (loW) conductivity data at the highest frequency of $25 \mathrm{kHz}$. The loW formations provided the youngest bedrock lithologies (Palaeogene and Cretaceous) encountered during the HiRES surveys. At the 1:50k scale, 22 LEX-RCS descriptions are present compared with only 11 RCS codes. Figure 4 compares the conductivity distributions for the single lithology units of Sandstone, Mudstone and Clay (Siltstone is absent). Across these units, median values increase from $26 \mathrm{mS} / \mathrm{m}$ (Sandstone), to $63 \mathrm{mS} / \mathrm{m}$ (Mudstone) to $132 \mathrm{mS} / \mathrm{m}$ (Clay). Classified AEM conductivity data are better represented by log-normal statistics as indicated in Figure 4. Typically the distributions are highly peaked with shoulders and multi-modal behaviour often displayed. Although data screening for EM noise (non-geological responses) is applied, all the distributions potentially contain outliers, particularly in the high value tails. Thus, as can be discerned in Figure 4, a high value maximum of $500 \mathrm{mS} / \mathrm{m}$ has been applied to condition the data set.

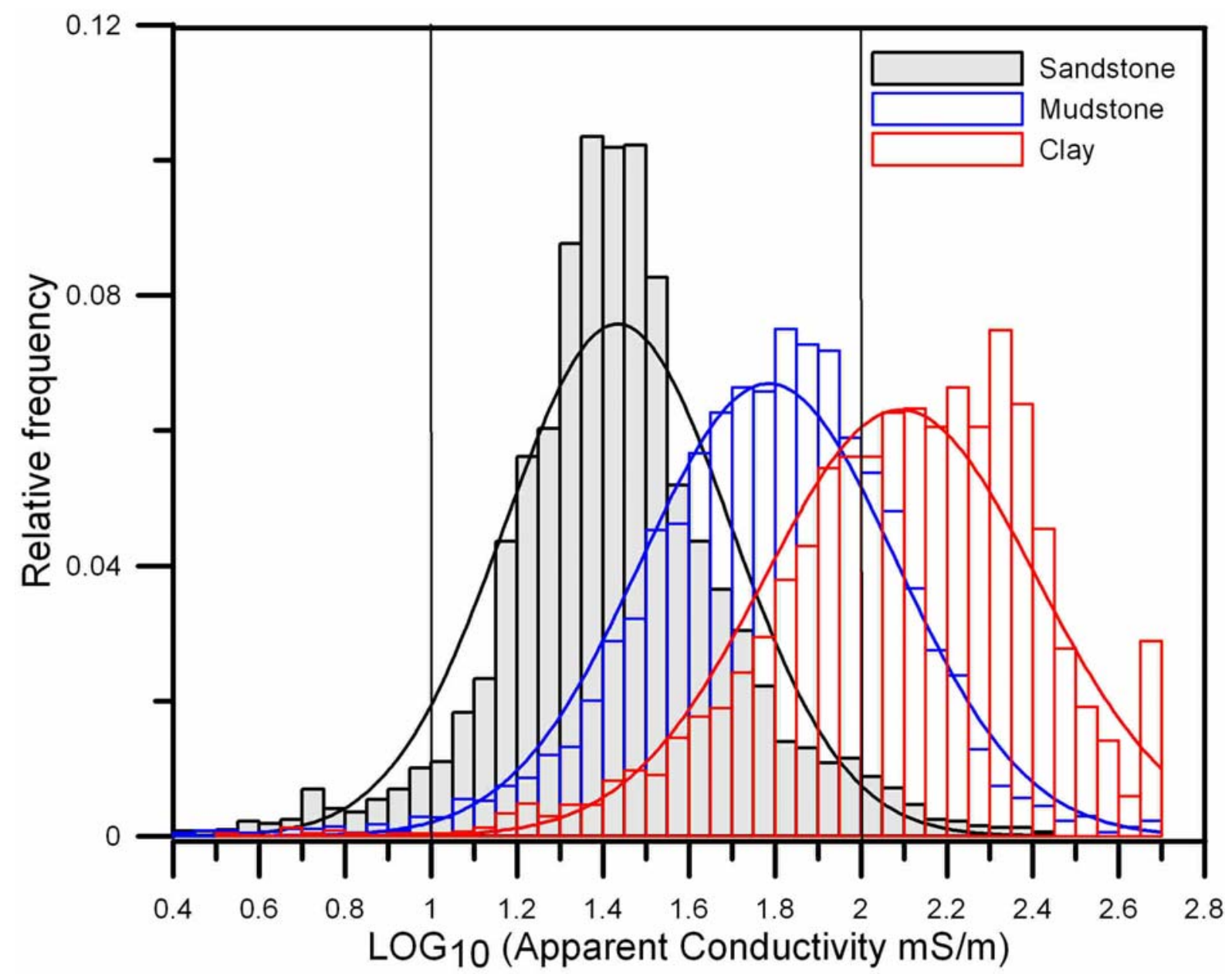

Figure 4 Normalised distributions of $3 \mathrm{kHz}$ apparent conductivity (logarithmic scale) for 3 bedrock lithologies, Sandstone, Mudstone and Clay. The best-fitting normal distributions are also shown. 
Chalk is the least conductive of the bedrock formations present on the loW. The two uppermost chalk units (Upper and Middle) provide the lowest conductivities observed across the survey area. There is a progressive and distinct increase in conductivity with increasing age across the three chalk units (Beamish and White, 2012). Thus the AEM conductivity data appear capable of distinguishing quite minor mineralogical (e.g. clay) variations within a resistive host (i.e. a material in which sensitivity to grain boundary effects is high). The low value tail in the Chalk distribution potentially maps the tightest (lowest porosity) material, although this has not been confirmed.

When assessing the wider UK data sets, sedimentary rock conductivities appear to follow the broad behaviours anticipated by the theoretical description of equation (1). Single lithology sedimentary rocks are generally represented by an increasing set of conductivities through the sequence Chalk, Sandstone, Limestone, Mudstone, argillaceous rocks and Clay. In the case of both Sandstone and Limestone, the single lithology conductivities are significantly less than their mixed lithology counterparts.

\section{The 1:625k UK bedrock conductivity map}

Despite the evident limited spatial coverage of the AEM surveys shown in Figure 3, it was natural to assess the geological and lithological coverage achieved by the surveys. At a scale of 1:625k, the UK digital bedrock lexicon comprises just 86 lithological (RCS) classifications. The lowest common AEM frequency of $3 \mathrm{kHz}$ is found to provide an $87 \%$ coverage (by area) of the lithologies. The conductivity map was constructed using the framework of the BGS DiGMapGB-625 bedrock lithological product. Further details and data download can found at http://www.bgs.ac.uk/products/digitalmaps/DiGMapGB 625.html.

A first-pass lithological classification of the conductivity data resulted in the attribution of 54 of the 86 lithological units. The unsampled lithological units cover an area of only $33,267 \mathrm{~km}^{2}(13.6 \%$ of the total). In a number of cases the remaining lithologies represent very small, localised occurrences of particular units (e.g. Anorthsite, $8 \mathrm{~km}^{2}$ and Mafite, $11 \mathrm{~km}^{2}$ ). Fourteen of the 32 units have spatial areas of less than $100 \mathrm{~km}^{2}$ and a significant proportion of the lithologies are confined to Scotland. Many of the unsampled units comprise multi-lithological components and natural associations with other sampled lithologies exist. A reassignment strategy was defined that resulted in the full statistical attribution of DiGMapGB-625 (Beamish, 2012). Central moments of the conductivities of the 86 formations are initially used to define the baseline conductivity map with median values ranging from 0.32 to $145 \mathrm{~ms} / \mathrm{m}$.

The final UK bedrock conductivity map is shown in Figure 5 using limits of 5 to $40 \mathrm{~ms} / \mathrm{m}$ to highlight resistive formations ( $<5 \mathrm{mS} / \mathrm{m}$ in grey) and increasingly conductive formations in colour. There is an evident association between the terranes of northern Scotland (excluding the Midland Valley), the Southern-Uplands-Down-Longford terrane, the central Lake District, parts of Wales and the south west granitic terrane which are all associated with the lowest conductivities $(<5 \mathrm{mS} / \mathrm{m})$. The general areas of eastern and southern England, associated with younger formations, are generally associated with the highest conductivities. 


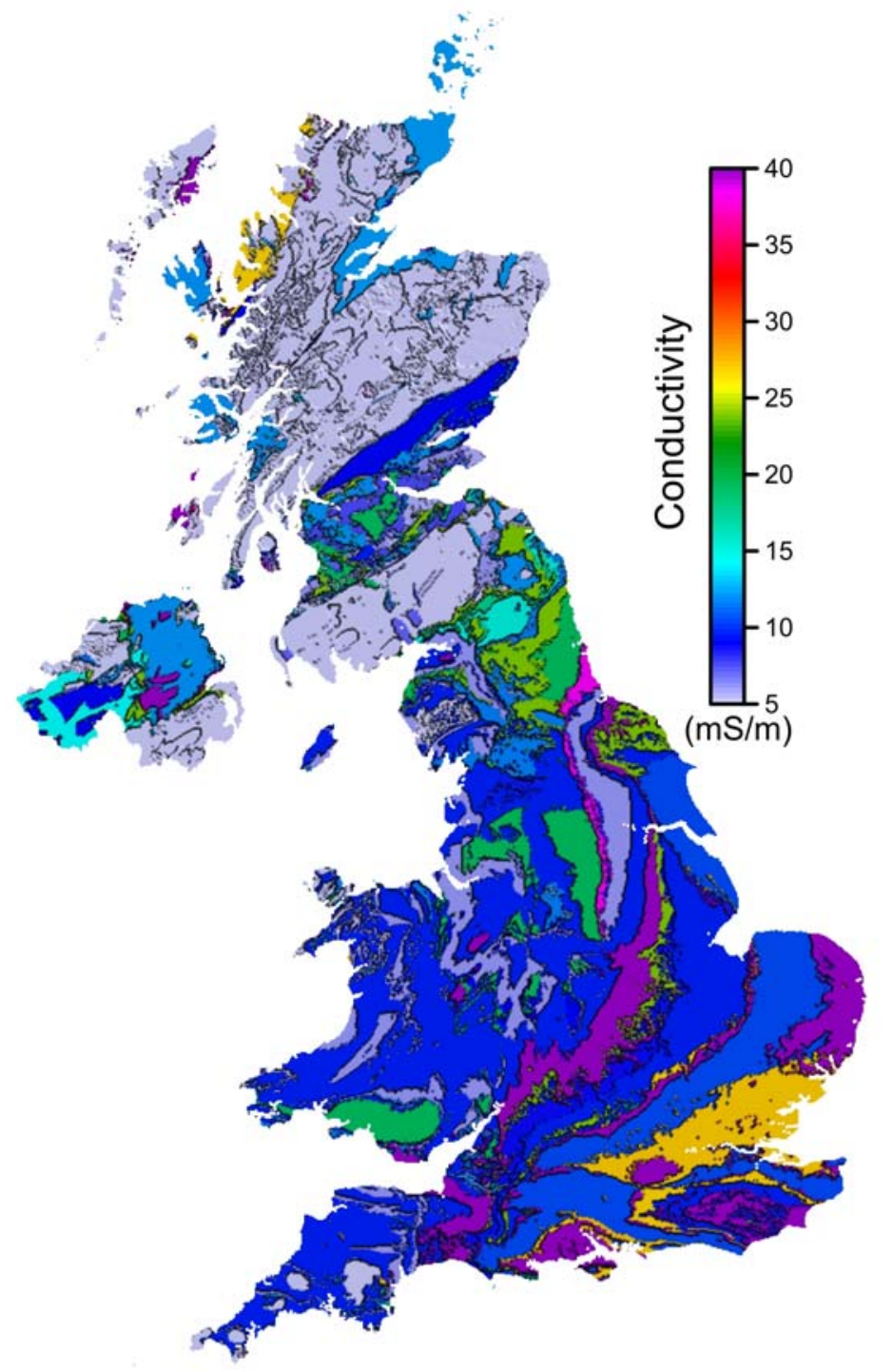

Figure 5 The 1: $625 \mathrm{k}$ near-surface bedrock conductivity distribution of the UK produced by lithological classification of $3 \mathrm{kHz}$ apparent conductivity data.

The new 1:625k UK conductivity model has already been used in relation to the calculation of Geomagnetically Induced Currents in the UK National Grid in response to extreme space weather events (Beggan et al., 2013). The applied use of bedrock conductivity information in relation to the protection of UK technological infrastructure is not new. The electrical properties of UK soils and rocks were investigated during the 1930s in both the laboratory and using geophysical field measurements (Smith-Rose, 1935). These early measurements were intended to provide a framework for understanding the potential impact of ground conductivity on the then developing radio and telephone transmission systems. In 1935, the British Electrical and Allied Industries Research Association (BEARA) presented two electrical resistivity maps of England-Wales and southern Scotland. The maps show contours of apparent resistivity of the ground for an apparent depth of 500' (152 m). The maps provide national scale information, and show a strong correlation 
with bedrock geology (knowledge of which was used in their construction). The maps produced were subsequently used for many decades by engineers dealing with electrical earthing installations (Tag, 1964; Griffiths and Pilling, 2004).

The new UK conductivity model is believed to be the first such map compilation since that produced in 1935. A comparison of the information available in the new and old maps, across a 90x90 km area centered on the Lake District is shown in Figure 6. Resistivity is used since the old paper map was constructed using the resistivity ranges shown. The new map uses the inherent quartile intervals of resistivity to illustrate the detail in the variations observed. The large central area is dominated by the Lake District Borrowdale Volcanics (lavas and tuffs) and these formations are identified as resistive in both maps, although the new map is clearly more spatially refined.
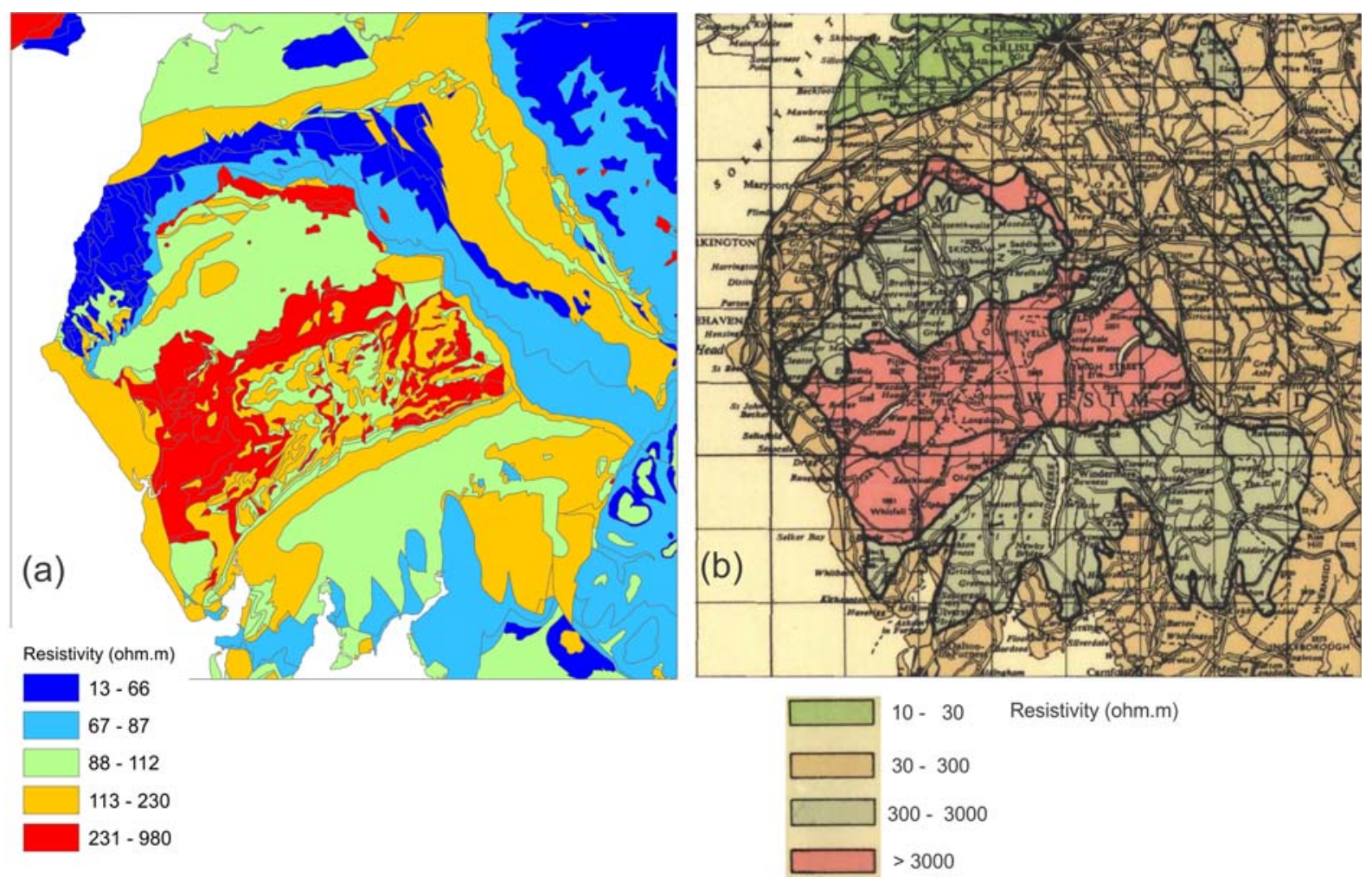

Figure 6 Comparison of bedrock resistivity variations across a $90 \times 90 \mathrm{~km}$ area centered on the Lake District (Cumbria). (a) from new 1:625k UK conductivity map. (b) from electrical resistivity map of England and Wales, reproduced from BEARA (1963).

\section{Mudrocks and shales}

The most detailed assessment of the conductivities of UK geological formations has been made using the extensive Tellus AEM data set of Northern Ireland (Fig. 3). The survey provided over $4.8 \mathrm{M}$ estimates of the bedrock conductivities over the wide range of geological formations present. A 1:250k scale lithological attribution of the conductivity information (Beamish, 2013) allowed detailed geostatistical and spatial analyses particularly with regard to igneous and sedimentary rocks. 
The igneous rocks were found to display the largest variability in conductivity values and many of the statistical distributions are multi-modal. A sequence of low value modes in these data are associated with intrusives within volcanic complexes. These and much older Neoproterozoic rocks appear to represent very low porosity formations that may be the product of rapid cooling during emplacement.

Sedimentary rock conductivities generally follow the broad behaviour anticipated by the theoretical description of equation (1) and the mixed lithology sandstone components shown in Figure 2. Complex spatial behaviour was however noted in relation to Carboniferous mudrock sequences. A detailed analysis was therefore undertaken in relation to the Carboniferous formations across a portion the Lough Allen Basin in the SW of the Tellus survey area.

The example area considered here contains 2 shale formations currently considered as shale-gas prospects at deeper levels in the basin. Although the main reservoir target is a sandstone (largely absent from the example area), the two shale formations are considered moderate to good source rocks and mature for oil and gas at surface and for wet or dry gas at depth (Clayton et al., 1989; Reay, 2004). 

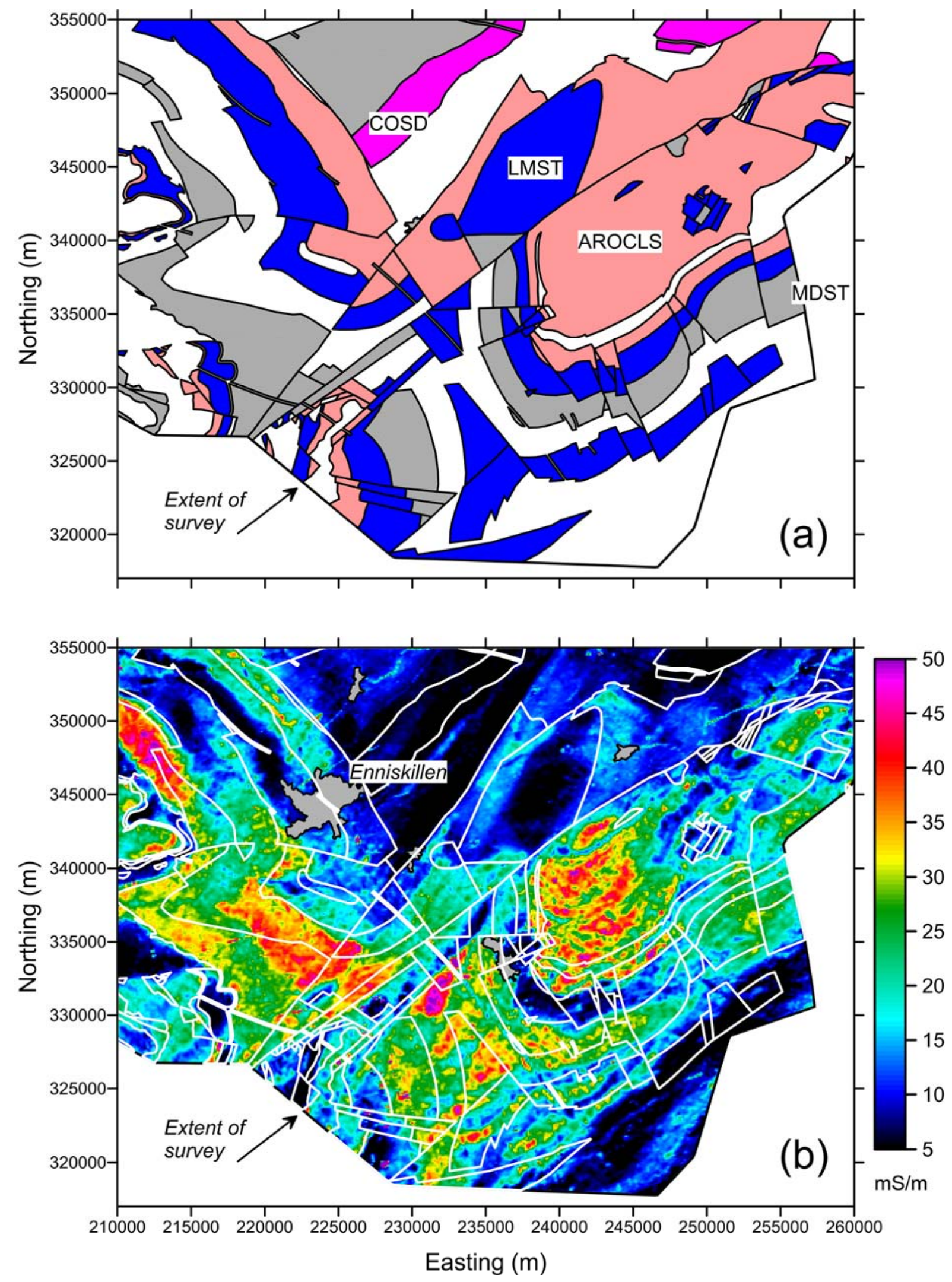

Figure 7 (a) 4 selected Carboniferous lithologies across a 50x38 km area in the SW of the Tellus survey area of Northern Ireland. Codes are described in Table 1. (b) $3 \mathrm{kHz}$ apparent conductivity data for the same area with lithological line-work superimposed. Grey areas are towns. Coordinates are Irish National Grid. 
Figure 7 a shows a set of 4 selected lithologies across the example $50 \times 38 \mathrm{~km}$ area. The 4 lithologies are identified in Table 1 (the area actually contains 17 lithological classifications). The observed conductivity distribution is shown in Figure $7 \mathrm{~b}$ with the 4 lithological boundaries overlaid. Although there are a number of conductivity contrasts associated with lithological boundaries, the conductivity data are largely characterised by distinct and spatially persistent intra-formation variations. Thus the conductivity data appear to be informative in relation to detailed lithological changes within the formations considered. These can be observed in the majority of formations from the more resistive LMST unit through to the highly conductive argillaceous AROCLS formation. Under the assumption that the vertical stratigraphic distribution of each formation remains unchanged across these zones, the conductivity data appear to reflect a sensitivity to the grain boundary influence term of equation (1).

\begin{tabular}{|l|l|l|l|l|l|}
\hline RCS Code & \multicolumn{1}{|c|}{ LITHOLOGY } & Area $\mathrm{km}^{2}$ & $\mathrm{~N}$ & $\begin{array}{l}\text { AC } \\
(\mathrm{mS} / \mathrm{m})\end{array}$ & \multicolumn{1}{c|}{$\begin{array}{c}\mathrm{SD} \\
(\mathrm{mS} / \mathrm{m})\end{array}$} \\
\hline AROCLS & $\begin{array}{l}\text { INTERBEDDED ARGILLACEOUS ROCK } \\
\text { AND [SUBEQUAL/SUBORDINATE] } \\
\text { LIMESTONE }\end{array}$ & 522.6 & 129,923 & 18.69 & 9.46 \\
\hline COSD & $\begin{array}{l}\text { CONGLOMERATE AND } \\
\text { [SUBEQUAL/SUBORDINATE] } \\
\text { SANDSTONE, INTERBEDDED }\end{array}$ & 293.1 & 15,152 & 5.27 & 1.80 \\
\hline LMST & LIMESTONE & 631.4 & 116,709 & 14.86 & 17.87 \\
\hline MDST & MUDSTONE & 421.4 & 89,645 & 21.66 & 10.56 \\
\hline
\end{tabular}

Table 1. Four selected lithological units discussed in the text. $\mathrm{N}$ refers to the number of conductivity samples and $\mathrm{AC}$ (apparent conductivity at $3 \mathrm{kHz}$ ) refers to the median of each distribution. SD refers to the standard deviation of the AC distribution.

In order to refine the analysis, it is necessary to further subdivide the mudstone sequences into mudstone and shale formations using their LEX-RCS descriptions. The subdivision into 6 formations is given in Table 2 with the shale formations highlighted. It can be noted that 2 of the shale sequences relate to an interbedded mudstone and limestone lithology (MDLM).

\begin{tabular}{|l|l|l|l|l|l|}
\hline $\begin{array}{l}\text { LEX-RCS } \\
\text { Code }\end{array}$ & Description & $\begin{array}{l}\text { Area } \\
\mathrm{km}^{2}\end{array}$ & $\mathrm{~N}$ & $\begin{array}{l}\text { AC } \\
(\mathrm{mS} / \mathrm{m})\end{array}$ & $\begin{array}{l}\text { SD } \\
(\mathrm{ms} / \mathrm{m})\end{array}$ \\
\hline AMM-MDST & $\begin{array}{l}\text { BALLINAMALLARD MUDSTONE } \\
\text { FORMATION }\end{array}$ & 1.3 & 453 & 12.2 & 3.2 \\
\hline BBSF-MDST & BENBULBEN SHALE FORMATION & 232.3 & 79,477 & 25.9 & 12.1 \\
\hline BLM-MDST & $\begin{array}{l}\text { BALLINAMALLARD MUDSTONE } \\
\text { FORMATION }\end{array}$ & 120.3 & 4,226 & 7.8 & 3.5 \\
\hline
\end{tabular}




\begin{tabular}{|l|l|l|l|l|l|}
\hline CADV-MDST & $\begin{array}{l}\text { CARRAUN SHALE FORMATION AND } \\
\text { DERGVONE SHALE FORMATION }\end{array}$ & 10.3 & 3,345 & 19.8 & 4.8 \\
\hline $\begin{array}{l}\text { BUNS- } \\
\text { MDLM }\end{array}$ & BUNDORAN SHALE FORMATION & 204.0 & 70,532 & 21.8 & 10.6 \\
\hline $\begin{array}{l}\text { DHSH- } \\
\text { MDLM }\end{array}$ & DRUMGESH SHALE FORMATION & 48.4 & 16,944 & 6.8 & 5.3 \\
\hline
\end{tabular}

Table 2. Six selected mudstone and shale units discussed in the text. $\mathrm{N}$ refers to the number of conductivity samples and $\mathrm{AC}$ (apparent conductivity at $3 \mathrm{kHz}$ ) refers to the median of each distribution. SD refers to the standard deviation of the AC distribution and the code MDLM refers to a Mudstone and limestone, interbedded lithology.

The statistical distributions of the first four MDST entries of Table 2 are shown in Figure 8 with the two shale formations identified in red. It is very evident that the conductivities of the shale mudstones exceed those of the mudstone formations by a factor of 2 to 3 . The enhanced conductivities of carbonaceous mudstone formations have previously been recognised but the results of Table 2 and Figure 8 provide statistical quantification. Enhanced conductivities (typically > $16 \mathrm{mS} / \mathrm{m}$ ) of the older (Silurian) carbonaceous Moffat Shale Group (again a MDST lithology) were previously noted by Beamish et al. (2010). The authors carried out a detailed analysis of the conductivity variations across the Southern Uplands-Down-Longford terrane occupying the SE quadrant of the Tellus survey area. The fault traces (tract boundaries associated with the Moffat Shale) defined by the elevated conductivities, were found to cut across those deduced by extrapolation of the limited exposures on the current geological map. A substantial geological reassessment of the existing mapping of the tract boundaries was therefore suggested.
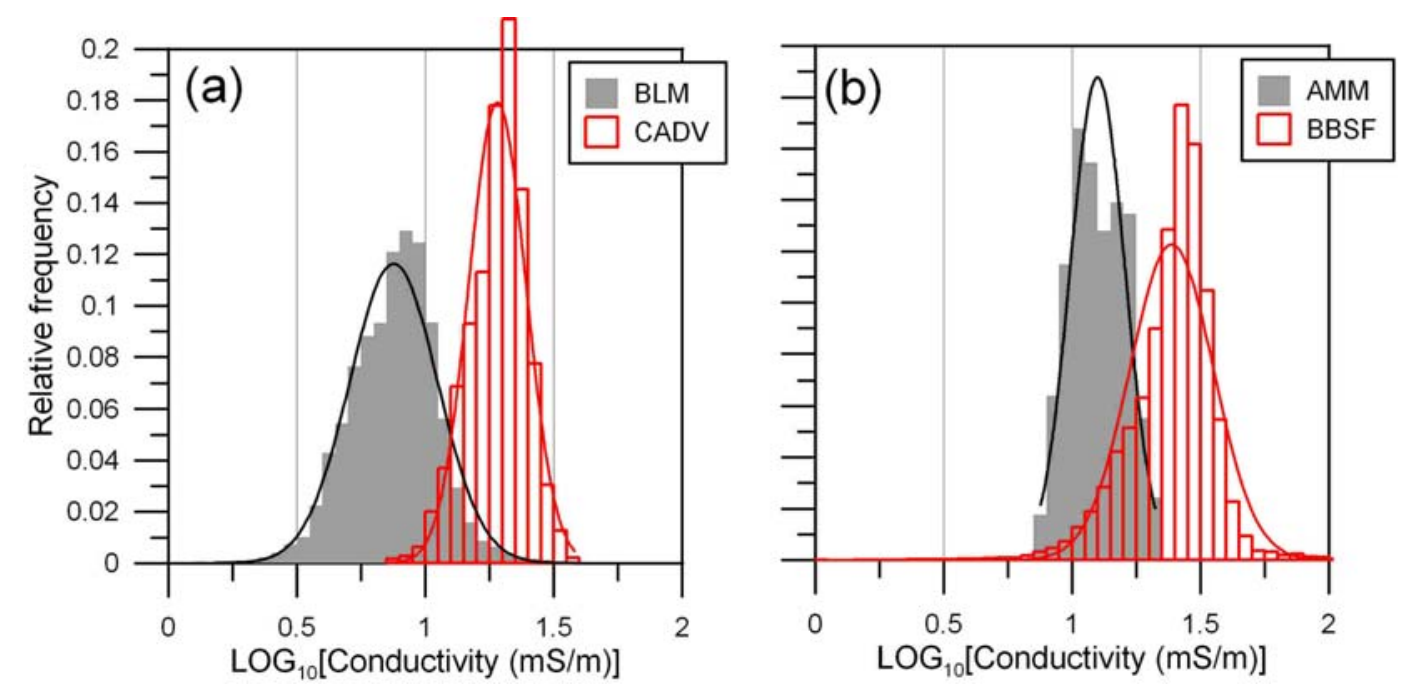

Figure 8 Normalised distributions of $3 \mathrm{kHz}$ apparent conductivity (logarithmic scale) for 4 Carboniferous lithologies (Mudstone and Shale) contained in 50x38 km area, Mudstone formations are shown in grey and Shale formations are shown in red. Codes are described in Table 2. The best-fitting normal distributions are also shown. 
The 6 formations listed in Table 2 are shown in Figure 9a across the 50x38 km example area, with line-work identifying faults and hence displacements at outcrop. The associated conductivity distributions, within each of the formations, are then shown in Figure 9b. The MDST formations ( $A M M$ and BLM) are persistently resistive but even across the more resistive BLM formation intraformation localised conductivity gradients are evident. Across the extensive BBSF shale formation, the highly variable conductivities are distinctive as are a number of strong 'edge' effects with values locally varying from $<5 \mathrm{mS} / \mathrm{m}$ to over $40 \mathrm{~ms} / \mathrm{m}$. The BBSF shale is currently considered a shale-gas prospect at hydrocarbon maturation depths (>250 m) towards the basin depocentre. A second shale unit, the Bundoran shale (BUNS-MDLM, Table 1), is also considered a prospect, again due to information (e.g. gas shows) from exploration wells in the area. The BUNS shale is largely adjacent to the BBSF shale at outcrop and displays very similar behaviour. Given the spatial complexity of the variations, it appears that the lithologies of these formations are highly variable and the geophysical behaviour is likely to be due to their sensitivity to the second term of equation (1). It can also be noted that the DHSH formation (DHSH-MDLM) although classified as a shale is observed to be distinctly resistive in comparison to the other shale formations. The geophysical information therefore suggests a more dominant limestone lithology (i.e. a grain dominated fabric) within this unit. 

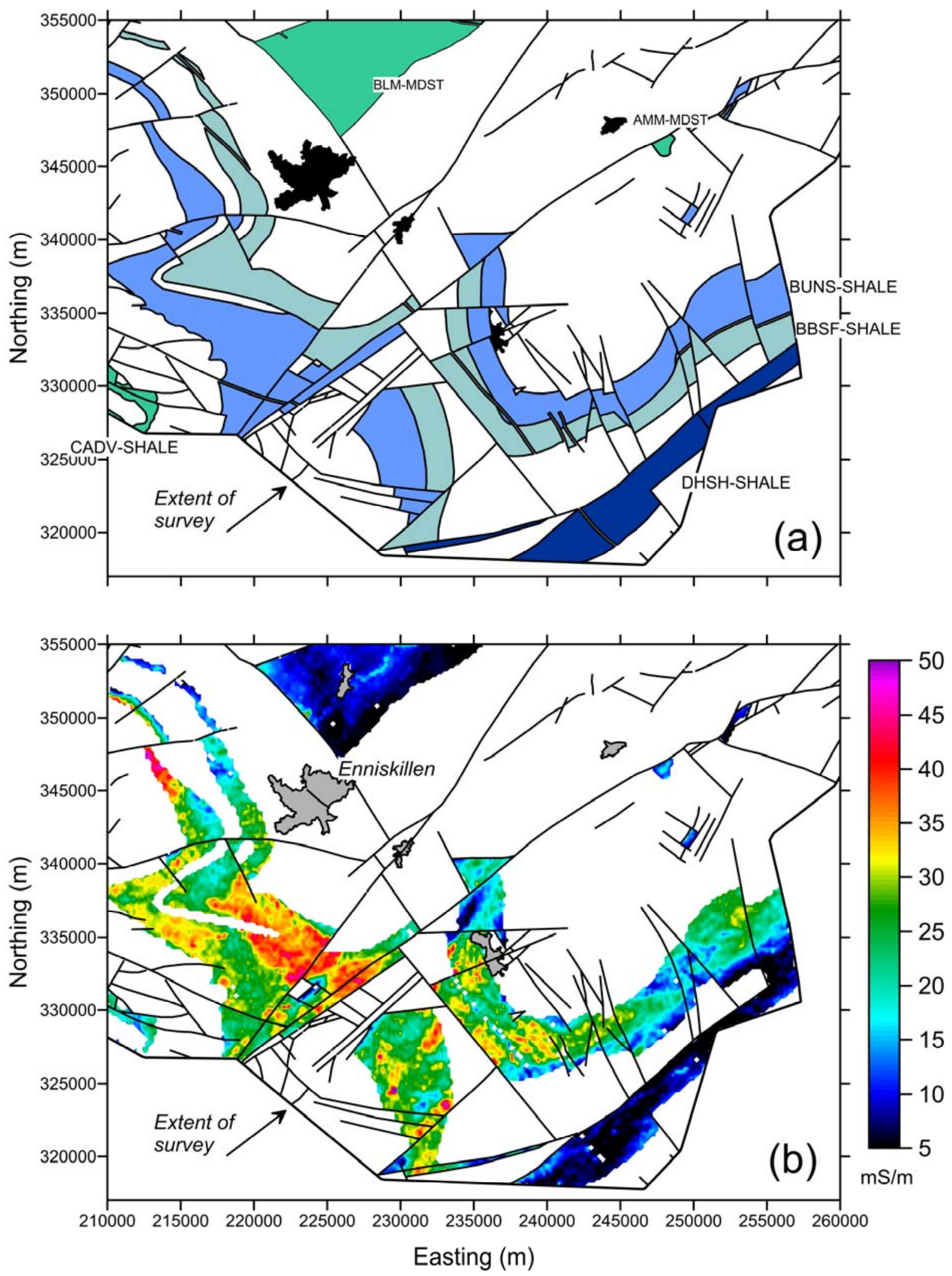

Figure 9 (a) Mudstone and Shale Carboniferous lithologies across a 50x38 km area in the SW of the Tellus survey area of Northern Ireland. Formations are described in Table 2. 1:250k fault traces are overlaid. Black areas are towns. (b) $3 \mathrm{kHz}$ apparent conductivity data for the same area with 1:250k fault traces superimposed. Grey areas are towns. Coordinates are Irish National Grid. 


\section{Discussion and conclusions}

In a typical petrophysical rock assessment, interpretation of conductivity would not be undertaken in the absence of additional control. In the general case of EM geophysical measurements (i.e. excluding specific geophysically-targeted mineral zones), such interpretations are often the norm. Given the extensive nature of AEM surveys and their inherent mapping functionality it seems natural to classify, and hence simplify, the spatially aggregated conductivity information on the basis of rock lithology. Such an attribution provides an inherent link between lithological rock parameters and the petrophysical parameters controlling bulk conductivity. The procedure also adds a significant degree of control in relation to the interpretation of the conductivity variations.

The application of such procedures has provided new information on the conductivity characteristics of many UK geological formations and allowed a new empirical map of the bedrock conductivity of the UK to be developed. When examined in detail, many sedimentary rock formations such as sandstones exhibit a conductivity behaviour consistent with theoretical descriptions. Complex spatial variability of conductivity has however been noted in relation to a Carboniferous suite of rocks containing mudstones and shales. Non-shale mudstones are distinctly less conductive than their shale counterparts. Enhanced shale conductivities are not universal; a shale formation (DHSHMDLM) studied here, is found to have a conductivity closer to that of mudstone. The extensive outcrops of the Benbulben and Bundoran shales display rapid and large-scale movements in conductivity, locally varying from $<5 \mathrm{~ms} / \mathrm{m}$ to over $40 \mathrm{mS} / \mathrm{m}$. It would appear that the response of the shale group rocks is particularly sensitive to rapid changes in the second term of equation (1). It could be argued that the observed spatial responses are entirely due to clay content however the shales in question are known to be organic-rich (Clayton et al., 1989).

Shallow (e.g. $<400 \mathrm{~m}$ ) AEM exploration of unconventional hydrocarbon plays (tight gas and oil sands) is currently ongoing, although largely unpublished. Such studies may be considered a further form of direct detection although the petrophysical ambiguity, common in marine CSEM applications, will often apply. Within this context, multi-phase, finite-difference numerical modelling of pore-scale processes is becoming increasingly sophisticated (Zhan et al., 2010). In addition to the solid grain matrix, additional phases now modelled include organic matter and adsorbed gas, clay bound water and free gas and water. Modelling of the electrical conductivity, and transport properties, of pore systems at the nanometer scale continues to be developed. Shabro et al. (2011) describe such studies in complex systems with grains coated in clay minerals and in the presence of organic matter. In such shale-gas rocks, conductivity is found to decrease with increasing total organic content. Given the observations discussed here, the potential interplay of increasing conductivity due to clay content and decreasing conductivity due to the presence of pore-scale hydrocarbons, deserves further research. 


\section{Acknowledements}

My thanks go to Chris Bull of ERA Technology Ltd for permission to publish the resistivity map image of Figure 6b. The geophysical data from Northern Ireland come from the Tellus Project which was funded by DETI and by the Building and Sustainable Prosperity scheme of the Rural Development Programme (Department of Agriculture and Rural Development of Northern Ireland). This report is published with the permission of the Executive Director, British Geological Survey (NERC).

\section{References}

Archie, G.E. [1942] The electrical resistivity log as an aid in determining some reservoir characteristics, Transactions of American Institute of Mining Metallurgical Engineers, 146, 54-62.

Beamish, D. [2002] Airborne EM applied to environmental geosciences in the UK. First Break, 20, 618-622.

Beamish, D. [2004] Airborne EM skin depths. Geophysical Prospecting, 52, 439-449.

Beamish, D. [2012] The 1:625k near-surface bedrock electrical conductivity map of the UK. British Geological Survey Report, OR/12/037. 23pp.

Beamish, D. [2013] The bedrock electrical conductivity structure of Northern Ireland. Geophysical Journal International, in press.

Beamish, D. and Klinck, B. [2006] Hydrochemical characterization of a coal mine plume detected by an airborne geophysical survey. Geofluids, 6, 1-11.

Beamish, D. and Young. M. [2009] Geophysics of Northern Ireland: the Tellus effect. First Break, 27, 43-49.

Beamish, D. and White, J.C. [2012] Mapping and predicting electrical conductivity variations across southern England using airborne electromagnetic data. Quarterly Journal of Engineering Geology and Hydrogeology, 45, 99-110.

Beamish, D., Kimbell, G.S., Stone, P. and Anderson, T.B. [2010] Regional conductivity data used to reassess Lower Palaeozoic structure in the Northern Ireland sector of the Southern Uplands-DownLongford terrane. Journal of the Geological Society, London, 167, 1-9.

BEARA [1963] The British Electrical and Allied Research Association, Electrical resistivity of England and Wales - apparent resistivity at a depth of 500 feet. Ref. D.263, February 1963 (Reproduced from ERA Report M/T32, 1934).

Beggan,C.D., Beamish,D., Richards,A. and Kelly, G.S. [2013] Prediction of Extreme Geomagnetically Induced Currents in the UK high-voltage network. Space Weather, submitted. 
Clayton, G., Haughey, N., Sevastopulu, G, D. and Burnett, R.D. [1989] Thermal maturation levels in the Devonian and Carboniferous rocks in Ireland. Geological Survey of Ireland Special Publication, $36 \mathrm{pp}$.

deLima, O.A.L. and Sharma, M.M. [1990] A grain conductivity approach to shaley sandstones. Geophysics, 55, 1347-1356.

Eidesmo, T., Ellingsrud, S., MacGregor, L.M., Constable, S., Sinha, M.C., Johansen, S., Kong, F.N. and Westerdahl, H. [2002] Sea Bed Logging (SBL), a new method for remote and direct identification of hydrocarbon filled layers in deepwater areas. First Break, 20, 144 - 152

Griffiths, H. and Pilling, N. [2004] Earthing. In: Haddad, M. and Warne, D. (Eds), Advances in High Voltage Engineering, IET Power and Energy Series, 40, 349-402.

Hallsworth, C. R. and Knox, R.W.O'B. [1999] BGS Rock Classification Scheme Volume 3 Classification of sediments and sedimentary rocks. British Geological Survey Research Report, RR 99-03.

MacGregor, L. [2012] Integrating seismic, CSEM and well-log data for reservoir characterisation. The Leading Edge, 31, 268-277.

Passey, Q.R., Creaney, S., Kulla, J.B., Moretti, F.J. and Stroud, J.D. [1990] A practical model for organic richness from porosity and resistivity logs. AAPG Bulletin, 74, 1777-1794.

Peart, R.J., Cuss, R.J., Beamish, D., Jones, D.G. [2003] Locating and mapping potential environmental hazards in the UK with high resolution airborne geophysics. Geoscientist, 13, 4-7.

Reay, D.M. [2004] Oil and Gas. In: Mitchell, W.I. (Ed.). The Geology of Northern Ireland - Our Natural Foundation. Geological Survey of Northern Ireland, Belfast. Chapter 22, 273-290.

Shabro, V., Torres-Verdin, C. and Javadpour, F. [2011] Pore-scale quantification of apparent permeability and electrical resistivity of hydrocarbon-bearing shale in the presence of gas desorption. Transactions of the SPWLA $52^{\text {nd }}$ Annual Logging Symposium, May 14-18, 2011, Colorado Springs.

Shepard, F.P. [1954] Nomenclature based on sand-silt-clay ratios. Journal Sedimentary Petrology, 24, 151-158.

Smith-Rose, R.L. [1935] The electrical properties of soil at frequencies up to 100 Megacycles per second; with a note on the resistivity of ground in the United Kingdom. Proceedings of the Physical Society, 47, 923-931.

Tag, G.F. [1964] Earth Resistances. George Newnes Ltd, London.

Waxman, M.H., Smits, L.J.M. [1968] Electrical conductivities in oil-bearing shaly sands. Society of Petroleum Engineering Journal, 8, 107-122.

Wentworth, C.K. [1922] A scale of grade and class terms for clastic sediments. Journal of Geology, 30, 377-392. 
Zhan, X., Schwartz, L., Toksöz, M., Smith, W. and Morgan, F. [2010] Pore-scale modeling of electrical and fluid transport in Berea sandstone. Geophysics, 75, F135-F142. 